\title{
LA CRISIS ECONÓMICA ESPAÑOLA EN LA PRENSA DE COSTA RICA. EFECTOS SOBRE LA IMAGEN DE ESPAÑA ${ }^{1}$
}

\section{THE SPANISH ECONOMIC CRISIS IN COSTARICAN PRESS. INFLUENCE ON SPAIN'S IMAGE}

\author{
María de los Ángeles Núñez Aberturas*
}

RESUMEN

\begin{abstract}
España tiene una presencia constante en la prensa de Costa Rica con una mayoría de noticias que trasmiten una buena imagen del país. Las informaciones sobre la crisis económica no han sido lo suficientemente frecuentes ni tan bien elaboradas como para perjudicar los efectos positivos de las noticias deportivas o culturales. Esta es la principal conclusión del análisis comparativo de las informaciones publicadas en cuatro periódicos representativos de los medios escritos de Costa Rica durante el segundo semestre de 2009 y tres años más tarde, en el segundo semestre de 2012.
\end{abstract}

PALABRAS CLAVE: ESPAÑA * COSTA RICA * PRENSA * IMAGEN * CRISIS ECONÓMICA

\section{ABSTRACT}

Spain has a constant presence in the Costa Rican press with a majority of the news transmitting a good image of the country. The reports on the economic crisis have been neither sufficiently frequent nor as well elaborated in order to injure the positive effects of the news on sport and culture. This is the main conclusion from the comparative analysis of the reports published in four newspapers, representatives of the written media in Costa Rica during the second semester of 2009 and three years later, during the second semester of 2012 .

KEYWORDS: SPAIN * COSTA RICA * PRESS *IMAGE * ECONOMIC CRISIS

Radio Nacional de España (RNE) y Universidad Francisco de Vitoria de Madrid.

anapjes@yahoo.es

1 Este artículo se basa en la tesis doctoral "La imagen de España en Costa Rica". Departamento de Historia Contemporánea de la Facultad de Geografía e Historia. Universidad Estatal a Distancia, España. 


\section{INTRODUCCIÓN}

Los medios de comunicación tienen una influencia decisiva en la trasmisión de imagen de un país. Como señala Javier Noya, en la imagen formada, influye "de forma significativa la visibilidad del país emisor de la imagen en el país receptor... La presencia de un país en los medios de comunicación de otro hará que su imagen sea más o menos definida o matizada en términos de la percepción de semejanzas culturales e intereses compartidos" (Noya, 2007: 42).

Los medios de comunicación serían, según las valoraciones del Latinobarómetro 2010 , los principales responsables de lo que los ciudadanos de un país sepan acerca de otro, en concreto, lo que los latinoamericanos conocen de Europa:

Los resultados de ese estudio fueron sorprendentes para los miembros del Consejo de Europa... No eran los esfuerzos de los gobiernos, las embajadas, ni la política exterior de los países de la Unión Europea, sino más bien lo que transmiten los medios de comunicación, lo cual está en el interés de la vida diaria de las personas. Es la experiencia del presente, el entretenimiento, la comida, lo que más cultura transmite en este mundo globalizado (Informe Latinobarómetro, 2010: 8).

Conocer la forma en que la crisis ha influido en la imagen externa de España no es posible, por tanto, sin tener en cuenta la forma en que la crisis ha sido reflejada en los medios de los países receptores de esa imagen. Las conclusiones de esta investigación sobre la imagen de España en Costa Rica, hubieran quedado incompletas sin analizar el efecto que la crisis económica ha tenido sobre la percepción que los costarricenses tienen de "lo español". Se imponía, entonces, hacer un análisis de cómo la crisis llegó a Costa Rica a través de sus medios de comunicación.

El estudio partió de las teorías sobre el concepto de "imagen país" basadas en los trabajos de Simon Anholt (2010) sobre nation brand o Charles Fombrum (1996), fundador del
Reputation Institute, desarrolladas después por multitud de autores. Fueron fundamentales, por citar solo algunos ejemplos en el ámbito hispano, los estudios sobre la imagen de España en América Latina realizados por Javier Noya, al frente del Observatorio de Imagen de España o los de Elvira Chadwik desde la Fundación Imagen de Chile. Para abordar el impacto de la prensa sobre la imagen de un país, se tomaron como referencia los documentos sobre el reflejo de España en la prensa de diferentes países realizados por el Observatorio Permanente de la Imagen Exterior de España en la Prensa Internacional (opiex) del Real Instituto Elcano. El estudio se completó con las entrevistas a los directores de los distintos periódicos costarricenses.

\section{LA PRENSA EN COSTA RICA. METODOLOGÍA Y SELECCIÓN DE PERIÓDICOS PARA EL ANÁLISIS}

La prensa de Costa Rica presenta algunas características propias en la región. Según el informe Medios de comunicación, el escenario iberoamericano dirigido por Bernardo Díaz Nosty:

En Centroamérica, la presencia de una calidad elevada de medios no garantiza el desarrollo cualitativo del mercado en términos de competencia y distribución de las estructuras de propiedad. Diferente es el caso de Costa Rica que, pese a contar con menos medios en comparación con los otros países de la región, muestra unos niveles de competencia y apertura favorables y uno de los índices de difusión más altos de toda Latinoamérica (2007: 104).

El país presenta el índice más alto de lectura de prensa escrita de la zona y tiene el mayor índice de circulación de prensa diaria de toda Centroamérica con 300 ejemplares por cada 1000 habitantes (incluyendo todo tipo de prensa), seguido por Guatemala y Panamá (Díaz, 2007).

Además, Costa Rica es el país centroamericano con mayor espacio de libertad de prensa: "los medios han gozado de condiciones favorables para la libre expresión y prácticamente no han experimentado periodos críticos de represión, 
censura y persecución" (Díaz, 2007: 105). Costa Rica se ha situado en posiciones muy altas en la clasificación de Reporteros Sin Fronteras sobre Libertad de Prensa, inclusive por encima de España.

Es cierto que, en los últimos años y como señala la periodista Giselle Boza:

... la concentración de las empresas informativas genera riesgos para toda la comunidad, al determinar la eliminación de una serie de voces de opinión pública, de modo que el público continúa teniendo varios medios a su alcance, pero en realidad es como si no tuviese más que uno (citado en Ordoñez, 2009: 332).

Esa concentración es evidente y determinó en buena parte la selección de los periódicos para la investigación.

Se estudió toda la información sobre España publicada en cuatro periódicos costarricenses durante el segundo semestre de 2009, un momento en el que la crisis económica en España empezaba a dejar sentir sus efectos $y$ tres años después, en el segundo semestre de 2012 , el periodo más fuerte de la depresión económica. Los periódicos seleccionados fueron La Nación, La República, el Diario Extra y el Semanario Universidad. Todos tienen propietarios y líneas editoriales distintas, dirigidos a diferentes sectores sociales.

La Nación, de tendencia liberal conservadora, es la cabecera de un grupo de comunicación que cotiza en bolsa, aunque el $30 \%$ de la propiedad está concentrado en la familia Jiménez.

Aunque no lo crea esa concentración es irrelevante, absolutamente, en el contenido de la publicación... En el 2002, empezamos a buscar los datos de la financiación de la campaña política de Abel Pacheco... descubrimos que había una estructura paralela recaudando fondos. Y ¿quién la dirigía?: el principal accionista de La Nación: Don Rodolfo Jiménez. Yo convoqué a la familia, y les dije: descubrimos esto $y$ lo vamos a publicar. Si ustedes tienen algún problema, me voy para mi casa $y$ chao. Y lo publicamos, sacamos la foto y lo llamaron a declarar al Congreso. ... Yo no veo a Polanco en las páginas de $E l$ País, reflejado en algo así... (Alejandro Urbina, entrevista, 2010).

Aunque La Nación y El Diario Extra tendrían un número de lectores muy similar que supera el medio millón (con tiradas que oscilan entre los 90000 y los 70000 ejemplares), la composición de esos lectores es diferente. $E l$ Diario Extra, fundado en 1979, es la carta de presentación del Grupo Extra, herederos de la familia Borrasé (su Prensa Libre cumplió en el 2014, 125 años de existencia). Con aire sensacionalista, tiene planteamientos de cierto rigor y variedad en sus páginas de información nacional y opinión.

La República, de enfoque económico, dirigido "a la clase empresarial, a clases altas, a los líderes de cada sector", según palabras de su ex director, Luis Alberto Muñoz, que definía su línea editorial como "socialdemócrata". Es propiedad de un pequeño grupo de comunicación canadiense, lo que de acuerdo a su director: "-le da una impronta especial porque busca homologarse a los criterios internacionales de calidad... Y respecto a la cobertura, también se busca un acercamiento al lector y eso hace que no haya una pérdida de referencia sobre la realidad nacional". Su tirada media es de 20000 ejemplares.

El Semanario Universidad cuenta con una tirada de unos 8000 ejemplares. Su público meta son los estudiantes de las cuatro universidades estatales de Costa Rica, aunque como explicaba la que fuera su directora, Laura Martínez Quesada:

... tratamos de llegar a esos públicos donde sabemos que hubo una votación alta hacia partidos no tradicionales. Se trata de un periódico subvencionado con medios muy reducidos. Su enfoque es diferente al del resto, con una orientación de centro izquierda. Así se estableció. El semanario nace en 1971. Había un clamor, una queja muy grande porque a los intelectuales, muchos de ellos 
de izquierda y de la Universidad, no les publicaban artículos en los medios de comunicación, fundamentalmente en La Nación, pero tampoco en los otros y se empieza a establecer la necesidad... Ahora no se mantiene esa efervescencia, pero en todo caso, el enfrentamiento, la pugna, el debate, sí se da y se aviva con los grandes acontecimientos como el referéndum sobre el $\mathrm{TLc}$, etc (entrevista, 2010).

De estos cuatro periódicos se contabilizaron todas las informaciones relacionadas con España, aunque la palabra "España" o "español" no apareciera expresamente citada en el titular. A partir de ahí se cuantificó el número de informaciones relacionadas con España publicadas en los cuatro periódicos durante el segundo semestre de 2009 y el mismo período de 2012, clasificándolas en tres categorías (noticias de actualidad de España, noticias que relacionan a España con Costa Rica y noticias que relacionan a España con América Latina) y por temas (política, economía, cultura, deportes y otras). También se consideró su enfoque y su efecto positivo o negativo para la imagen de España sin olvidar que, como todo lo relacionado con las percepciones, este análisis tiene una dosis de subjetividad que si bien complica el estudio científico, lo hace también más atractivo.

\section{ESPAÑA EN LA PRENSA DE COSTA RICA: 2009-2012}

En el segundo semestre de 2009, era presidente del gobierno español José Luis Rodríguez Zapatero, la crisis económica empezaba a mostrar su gravedad, ETA mantenía su actividad terrorista, se iniciaban los procedimientos contra el juez Baltasar Garzón y entre otros muchos temas, había saltado el caso Gürtel de corrupción en el Partido Popular (PP). Tres años después, segundo semestre de 2012, se cumplía el primer año de gobierno de mayoría absoluta del pp, con Mariano Rajoy al frente de una política de ajuste que provocó una fuerte reacción entre la población española: la crisis era un hecho, en el ámbito autonómico y de los nacionalismos, las informaciones sobre ETA habían sido sustituidas por la independencia catalana y los problemas de corrupción afectaban a la familia real y ocupaban las portadas de los periódicos españoles.

Esos tres años de diferencia marcaron un cambio radical en la realidad española y la mentalidad de los españoles. El país era diferente y sus habitantes lo percibían así. ¿Hasta qué punto esa idea se trasmitió en el exterior? ¿Reflejó la prensa costarricense ese cambio tan fundamental? ¿Qué contaron los periódicos costarricenses sobre España?

\section{NÚMERO TOTAL DE INFORMACIONES RELACIONADAS CON ESPAÑA}

El primer punto a considerar para responder estas cuestiones es el número de informaciones relacionadas con España publicadas en los cuatro periódicos costarricenses durante el periodo analizado. Si durante el segundo semestre de 2009 se contabilizaron 664, durante el mismo periodo del 2012, su número creció hasta 827 , lo que supone una media de casi 30 entradas más por mes, un incremento significativo. El aumento se registró tanto en La Nación (26\%), como en La República (18\%), mientras las entradas se mantuvieron prácticamente iguales en el Diario Extra y el Semanario Universidad.

Se puede concluir que de forma regular a lo largo de los años y en ambos periodos, se supera el centenar de entradas relacionadas con España por mes. Por tanto, España tiene una presencia notable en la prensa costarricense. Se puede afirmar que, después de eeuu, Nicaragua, Colombia y probablemente Venezuela, España sea el país con mayor número de entradas en los diarios costarricenses que, en términos generales, reservan la mayoría de su espacio a la información local. 


\section{GRÁFICO 1 \\ NÚMERO TOTAL DE ENTRADAS POR PERIÓDICO \\ 2009 Y 2012 \\ (NÚMEROS ABSOLUTOS)}

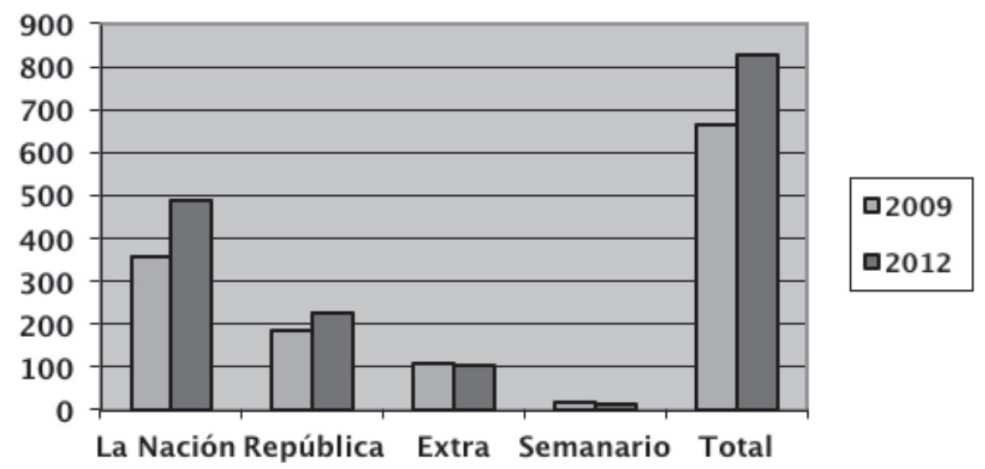

Fuente: Elaboración propia.

En el análisis hay que considerar que el Semanario Universidad solo publica cuatro ejemplares mensuales y si bien, su número total es reducido, la presencia de noticias relacionadas con España se equipara proporcionalmente a la del Diario Extra.

De esta manera, sería esperable que el capítulo más numeroso de informaciones publicadas fuera el de las noticias que relacionan a España con Costa Rica; no obstante, el tema sobre la actualidad de España ocupa más lugar en los periódicos, lo que demuestra su interés por lo que en ese país ocurre al margen de que esto afecte o no a los costarricenses.
El número de informaciones sobre la actualidad española aumentó notablemente en 2012; salta del 58\% del total en el 2009 (390 noticias) al 70\% tres años después (573 noticias). Las informaciones que relacionan a España con Costa Rica se mantienen estables en términos proporcionales, en torno al $26 \%$ del total. Por el contrario, llama la atención el reducido porcentaje de informaciones que relacionan a España con América Latina, sobre todo en el 2012, cuando estos temas casi desaparecen de la prensa: se reducen a poco más del $4,5 \%$ del total, diez puntos menos que en el 2009.

\section{GRÁFICO 2 \\ NÚMERO TOTAL DE ENTRADAS POR TEMAS 2009 Y 2012}

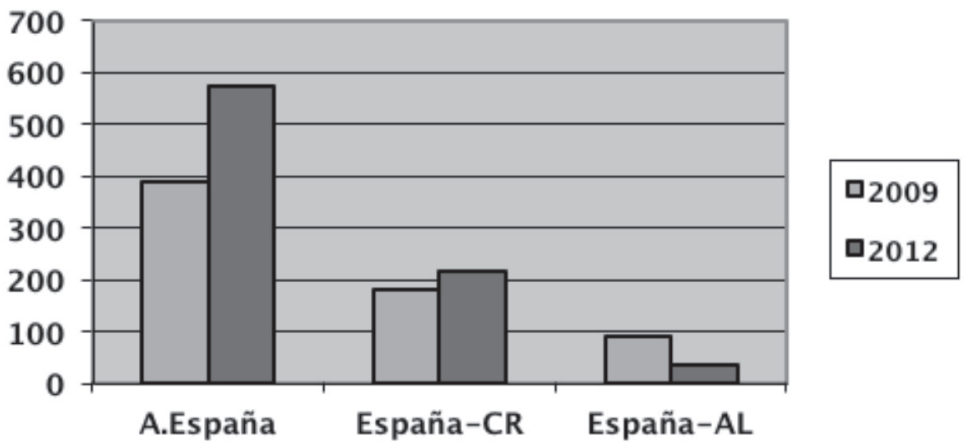

Fuente: Elaboración propia. 
INFORMACIONES PUBLICADAS SOBRE LA ACTUALIDAD DE ESPAÑA

Las informaciones deportivas mantienen en ambos periodos el predominio en las noticias sobre España, más de la mitad del total. Lo que cambia notablemente de un año a otro es el número de noticias relativas a la economía, un tema prácticamente inexistente en la prensa costarricense durante 2009 y que pasa a ocupar el $27 \%$ del total de las notas relacionadas con la actualidad española en 2012.

GRÁFICO 3

ENTRADAS SOBRE LA ACTUALIDAD ESPAÑOLA POR TEMAS 2009 Y 2012

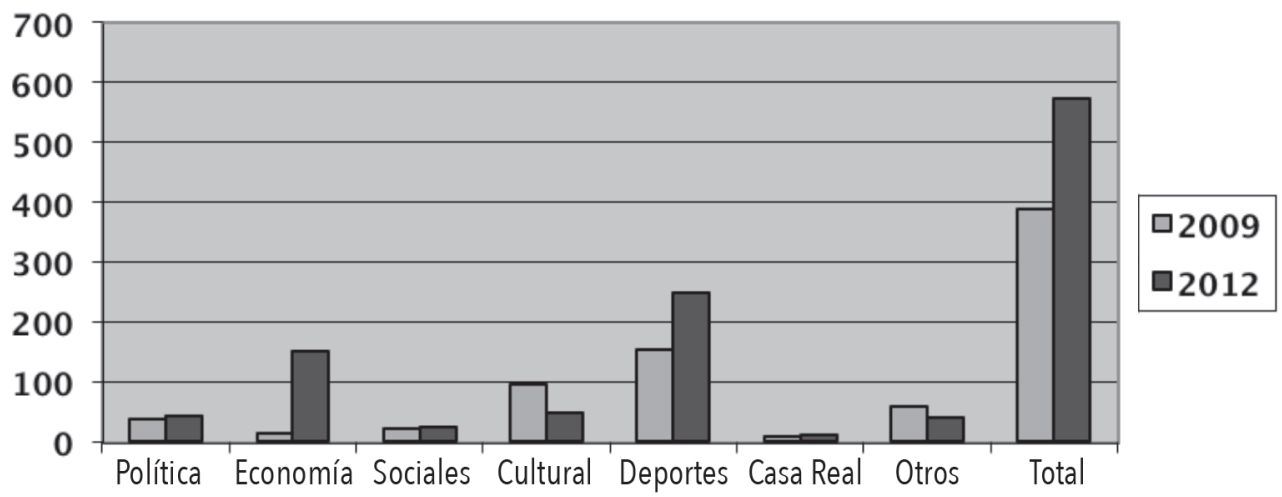

Fuente: Elaboración propia.

\section{INFORMACIONES DE POLÍTICA ESPAÑOLA}

Las informaciones sobre la actualidad política recolectadas en la prensa de Costa Rica son pocas, en torno al $9 \%$ del total de noticias publicadas en ambos periodos. Respecto a los temas, se encontraron varias coincidencias. La primera, tanto en 2009 como en 2012 , el asunto mayoritario es el de las autonomías, aunque con diferentes contenidos. Si en 2009, los atentados de ETA fueron el tema central en la mayoría de las informaciones, en 2012 fue el proyecto independentista catalán. En ambos casos, La Nación dedicó mayor y mejor cobertura a ambas cuestiones mientras que el Diario Extra lo hace sin una línea coherente o un seguimiento lógico.

En los dos años, la publicación de estas noticias tuvo un impacto negativo para la imagen de España. En el primero, al trasmitir una idea de violencia, atentados, inseguridad $y$ desorden. Por ejemplo, se dio cobertura al atentado de eтA en Burgos en julio de 2009 y el 10 de agosto, los tres diarios coinciden en publicar un nuevo atentado en Mallorca. En las noticias de Cataluña, los efectos son negativos por cómo está planteada la información: por un lado, los titulares suelen incluir términos como "ruptura", "separación", "fracaso": ("Cataluña recibe un contundente no de Madrid en soberanía fiscal", La Nación del 12/09/2012 o "Fracasa la separación de Cataluña", con motivo de las elecciones autonómicas, La República del 26/11/2012). Por otro lado —esto es un problema generalizado en muchas informaciones - la cobertura informativa al tema no tiene un seguimiento continuo y se reduce, en demasiadas ocasiones, a notas aisladas, mal contextualizadas o difíciles de comprender para un lector no familiarizado con el sistema autonómico español.

Respecto a las informaciones sobre la Casa Real, el número de entradas es reducido en ambos periodos, no llega ni al 3\% de las 
informaciones sobre la actualidad española. Casi todas las noticias aparecen en La Nación y su contenido tiene más que ver con lo que llamaríamos "prensa rosa", que con actividad o influencia institucional: el divorcio de la Infanta Elena, Doña Letizia en las Olimpiadas, entre otras. El único papel político atribuido a los Reyes o al Príncipe Felipe tiene que ver con América Latina: se relacionan con Cumbres Iberoamericanas o en el caso del Príncipe, con su presencia en la toma de posesión de los mandatarios regionales. El saludo entre el Rey y Hugo Chávez, el 12 de septiembre de 2009, es portada en La República bajo el titular "Jocoso encuentro" y el Príncipe es la imagen de la toma de posesión del presidente panameño, en julio de 2009. Incluso en estos casos, por el enfoque de las informaciones, la presencia de la familia real resulta un adorno gráfico que no se acompaña por ningún otro matiz en el contenido de la noticia. La polémica "caza de elefantes" del Rey pasa también muy desapercibida con solo una nota breve en La Nación el 22 de julio de 2012, titulada "wwF retira presidencia al Rey de España tras polémica por cacería de elefantes en África”.

De lo que no aparece ni una línea en los meses analizados es del caso Urdangarín, el marido de la Infanta Cristina implicado en casos de corrupción. Incluso, en la prensa costarricense no aparece ni una sola información sobre los escándalos de corrupción que han afectado a los partidos políticos en España y que tanto espacio ocuparon en los medios españoles, lo cual puede revertir en positivo para la imagen de España en Costa Rica.

Otros temas relacionados con la política española: inmigración, Gibraltar, política exterior o incluso, la evolución de la ley del aborto se cubren de forma esporádica, anecdótica y fuera de contexto.

\section{INFORMACIONES SOBRE LA ECONOMÍA ESPAÑOLA:} LA CRISIS EN LA PRENSA

El número de informaciones relativas a la situación económica en España incrementó en el segundo semestre de 2012, en relación al mismo periodo de 2009, hasta llegar a las 154, con un aumento significativo de entradas en el diario La Nación. La crisis económica pasó a ocupar más de un $25 \%$ de las informaciones relativas a España en 2012, cuando en 2009 era una cuestión residual.

En el segundo semestre de 2009, la crisis era evidente en España. Los peores pronósticos empezaban a confirmarse y todas las cifras económicas lanzaban señales de alarma. Sin embargo, el número de noticias sobre el tema recogidas en la prensa costarricense era mínimo, de 390, solo 13 tenían relación con la economía y de estas, seis se publicaban en La República.

Curiosamente, fue el Diario Extra en agosto de 2009, el primero que publicó información sobre la crisis relacionándola con la situación en Europa y bajo el titular: "El desempleo consume Europa. España continúa a la cabeza". Sin embargo, en su errática línea, este periódico no vuelve a citar el asunto salvo en otra información sobre problemas económicos en la UE, aunque no cita a España. En noviembre apareció citada en una nota la palabra "crisis"; fue en La República y con una noticia que tiene mucho de anecdótico: "Ante la crisis, los españoles se dedican más a la cocina". La siguiente será en el mismo periódico, el 13/11/2009, hablando abiertamente de que "La Economía de España se contrae por sexto semestre consecutivo". El tema aparece de nuevo el día 14 en La Nación con el titular "España como excepción a la salida de la crisis en la eurozona".

El reflejo de la situación económica española cambió en el segundo semestre de 2012. Casi todos los días del mes de julio, el tema de la crisis española es noticia en al menos un periódico. El número de noticias se acerca a 50 , casi un tercio del total del semestre. En dos días (13 y 20), coinciden en sus informaciones La Nación, La República y el Diario Extra, algo absolutamente inusual. De hecho, el día 13 , los tres periódicos presentan la misma información: las protestas contra los recortes del gobierno con fotos de las manifestaciones. Las imágenes de protestas o manifestaciones aparecen en 13 ocasiones en julio, la mayoría de ellas en La Nación. El día 12, una fotografía especialmente violenta ocupa la portada del diario con llamativo pie de foto: "Violencia en España: 
esta imagen no ocurrió en Centroamérica ni en los países árabes. Sucedió en pleno centro de Madrid, en España asediada por la crisis". Durante el resto de los meses del segundo semestre de 2012, el ritmo de informaciones relacionadas con la crisis baja un poco, aunque llega al centenar.

Mariano Rajoy y el Ministro de Economía, Luis de Guindos, son protagonistas gráficos de las noticias en numerosas ocasiones, cuatro cada uno a lo largo del mes. La crisis es objeto en este mes de tres artículos de opinión, dos en el Diario Extra y un editorial de La Nación.

La Nación ofrece la información de la crisis desde varios puntos de vista $y$ abordando el tema de forma más completa con informaciones relativas a los déficits de las comunidades autónomas, la privatización de la sanidad, los desahucios, la emigración de los jóvenes, entre otros. La República tiene un enfoque más económico, centrado en la deuda, cifras de desempleo, financiación de la banca, el caso de las preferentes, entre otros. El Diario Extra mantiene su línea peculiar con titulares como "El gobierno español se soca la faja" o "Aumenta la obesidad entre las mujeres españolas a consecuencia de la crisis". En El Semanario solo se aborda el tema con un artículo de opinión sobre los desahucios y los problemas sociales que genera la recesión.

Junto a la frecuencia de las entradas relativas a la crisis, el efecto más negativo para la imagen de España lo produce el vocabulario de los titulares o de la información sobre el tema. Son habituales los términos violencia, recesión, ayuda, desempleo, deuda, tensión o adjetivos como drástico y catastrófico, algunos verbos como golpear, someter, controlar, disparar, acosar, etc. Todo esto trasmite una imagen dura de la situación en España, un nombre que aparece como nunca registrado en el titular de la información.

Como contrapartida, subrayar que España no aparece sola en la crisis. Son igual o mayormente numerosas, las entradas de $L a$ Nación y principalmente, de La República, a la crisis en Italia, Grecia, Portugal o a la crisis del euro, en las que no se cita a España.

Dentro de las informaciones sobre la crisis también hay titulares con un sentido positivo como "Recibe España buena nota por los ajustes" o "España cumple", que si se hace una lectura superficial de la prensa, devienen en una buena imagen para el país; pero este tipo de titulares son escasos en medio de toda la información relacionada con el tema. Asimismo, lo que matiza en parte la imagen negativa de España en crisis, es que un número bastante alto de las informaciones son notas breves $y$ con titulares en ocasiones difíciles de situar en contexto, como: "Se impone deuda española" (La República, 20/11/2012) o "Millonarios recapitalizan banca europea” (idem., 04/10/2012).

En cualquier caso, las informaciones relativas a la crisis de la economía española adolecen de los mismos problemas de calidad informativa que sufren el resto de los temas, positivos o negativos para España o cualquier otro país, publicados en la sección Internacional de la prensa de Costa Rica. Salvo La Nación, que llega a presentar algunos reportajes elaborados desde España por periodistas de plantilla, en La República la información está tomada directamente de la agencia EFE, sin adaptar su vocabulario o tratamiento a las características del lector costarricense, con titulares a veces oscuros o sacados de contexto; por otro lado, en el Diario Extra, el seguimiento de las noticias es errático y sujeto a criterios desconocidos. Una gran parte de las noticias son breves y sin el contexto para su comprensión.

No todas las noticias publicadas sobre la economía española son negativas: "Empresas españolas controlan el 36\% de las infraestructuras de todo el mundo" o "El español Amancio Ortega desplaza a Warren Buffet en el tercer puesto de las personas más ricas del mundo", pero las noticias económicas positivas son pocas ese año.

\section{INFORMACIONES SOBRE LA CULTURA Y EL DEPORTE ESPAÑOL}

El aumento importante en el número de entradas sobre temas relacionados con la economía española entre 2009 y 2012, parece ir en detrimento de los temas culturales, que se reducen de forma muy notable en el segundo periodo analizado: del 30\% de las informaciones relativas a la actualidad española durante 
el segundo semestre de 2009 a apenas el 9\% tres años más tarde.

En ambos periodos, determinados nombres propios llevan el peso de la información cultural, muy concentrada en las actividades de artistas $y$ actores como Serrat y Sabina, Alejandro Sanz, Penélope Cruz, Javier Bardem o Pedro Almodóvar. El problema es que son personajes muy reconocidos que tienen un peso individual fuerte, con lo cual no puede decirse que representan a la cultura española sino que su obra está por encima de su nacionalidad. Aunque el número de informaciones sobre la cultura española es bastante importante, su peso para la imagen de España sería cuestionable. Por otra parte, son noticias que abarcan demasiados terrenos: desde la restauración de los leones de la Alhambra o la muerte de Juan Carlos Calderón a la búsqueda de los restos de García Lorca, lo que difumina y por tanto, dificulta la difusión de una imagen propia. Principalmente, porque una gran parte de esas notas son noticias breves, bordeando lo que sería la noticia de sociedad más que de cultura y con muy poca trascendencia.

Sobre el cine español, la información se reduce a los nombres citados $y$ apenas tiene cabida en la prensa costarricense el estreno de películas menos comerciales o la celebración de festivales de cine importantes en España. $\mathrm{Si}$ el lector costarricense apenas puede tener una imagen sobre el panorama cinematográfico español, la situación es más grave en el mundo de la literatura, prácticamente inexistente en la información cultural costarricense. El único medio que atiende un poco el apartado cultural es el Semanario Universidad, mientras en el resto de los medios, los escritores españoles apenas tienen espacio, ni siquiera en el Suplemento Cultural de $\mathrm{La} \mathrm{Na}$ ción, donde el apartado de reseña de libros es copado por los nativos.

Sin embargo, la estrella informativa es, la información sobre el deporte español. En los dos períodos analizados, representa más del $40 \%$ de las informaciones sobre la actualidad española. En el segundo semestre de 2012, si la crisis ocupó 154 entradas, los deportes tienen
100 más: 250 , el $44 \%$ del total. Son noticias expuestas en todos los medios, por lo que llegan a prácticamente todos los lectores de prensa, las coberturas son amplias, hay información propia, el lenguaje está adaptado al lector local y las fotografías son llamativas.

Como se puede observar, en el apartado sobre economía, durante julio casi todos los días había al menos una entrada relacionada con la crisis; no obstante, en el caso del deporte hay dos o más entradas diarias. Durante julio aparecen un buen número de fotografías relativas a manifestaciones y ese mismo mes se inicia con el triunfo de la selección española en la Eurocopa, por segunda vez en su historia. Titulares como "España ya es leyenda" (La República, 02/07/2012), "Les espera la inmortalidad" (Diario Extra, 03/07/2012) o "España cambia la historia" (La Nación, 05/07/2012), tienen un peso difícil de valorar sobre la imagen de España. Esos días se pudieron leer artículos de opinión, comentarios destacados como: "Un pasodoble inolvidable", "iQué orgullo España. Jugar con tanta grandeza, con semejante clase y deportivismo!", "Qué bonito debe ser sentirse hoy español!" (La Nación, 04/07/2012) que sirvieron como abrumadora contrapartida a cualquier otra noticia negativa. A partir de ahí, el inicio de la "Liga Galáctica" o los triunfos del Barça, del Real Madrid en la Liga, en Champions o en la Supercopa, las informaciones relativas a Messi o Cristiano Ronaldo con las camisetas de sus equipos, se recogen prácticamente a diario con portadas y grandes espacios, publicidad a toda página relativa a la retrasmisión de los partidos más llamativos; no hay imagen negativa que no se contrarreste con esta avalancha de información.

Aunque el futbol es, obviamente, la fuente principal de información, cualquier lesión, partido, entrenamiento o victoria de Rafael Nadal tiene espacio asegurado, lo mismo ocurre con Fernando Alonso. Asimismo, la afición que en Costa Rica hay al ciclismo hace que se ofrezca una importante cobertura de la Vuelta Ciclista a España y amplios espacios dedicados a las figuras de este deporte en España. 
INFORMACIONES SOBRE LA RELACIÓN ENTRE ESPAÑA Y COSTA RICA

Durante el segundo semestre de 2012, aumentan ligeramente las informaciones que relacionan a España con Costa Rica en cualquier ámbito. De 184 entradas se pasa a 216, en torno a un $25 \%$ del total de informaciones sobre España.

GRÁFICO 4

ENTRADAS ENTRE ESPAÑA-COSTA RICA POR TEMAS

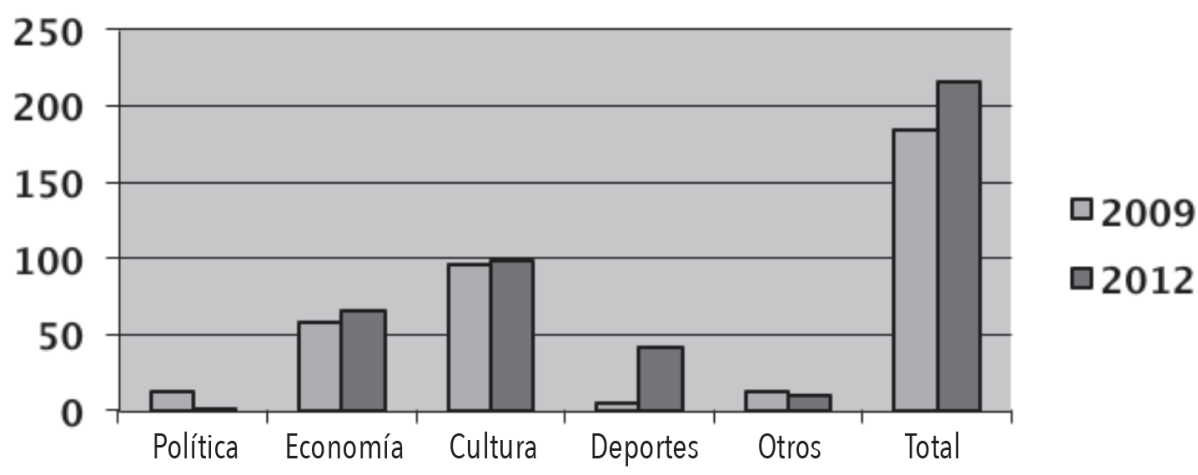

Fuente: Elaboración propia.

El periódico La Nación demuestra poco interés por los temas que relacionan a España con Costa Rica, a los que dedica no más del $27 \%$ de las entradas que tienen que ver con España. El Diario Extra y El Semanario dedican más espacio a estos temas, especialmente el periódico universitario, con cierto riesgo para la imagen de España por la voluble línea editorial del primero, más atento a temas escandalosos o llamativos, $y$ la tendencia sumamente crítica hacia determinados aspectos de la inversión extranjera del segundo.

\section{INFORMACIONES SOBRE RELACIONES POLÍTICAS Y ECONÓMICAS ENTRE ESPAÑA Y COSTA RICA}

Durante el segundo semestre de 2009, son 13 las informaciones sobre este tema; no obstante, en el mismo periodo de 2012, se da solo una publicación en un artículo de opinión sobre cooperación, una cuestión que apenas tiene cobertura a pesar de la inversión económica y técnica que España realizó en el país durante los años anteriores.

A juzgar por lo publicado, la imagen del lector costarricense es que España y Costa Rica no tienen relaciones políticas. Las únicas notas que podrían incluirse en este apartado son aquellas en las que se habla del interés español en las negociaciones del Acuerdo entre Centroamérica y la Unión Europea (uE); concretamente dos notas, el 22 de setiembre y el 28 de octubre de 2009 en La Nación. En contrapartida, tampoco hay notas negativas a destacar.

Por otro lado, lo que ocupa un espacio fijo y notable, que no se repite para ningún otro país, es el apartado de informaciones relacionados con la historia compartida: cada mes de setiembre se revisa el proceso de Independencia, se publican artículos sobre la época colonial, marcando una diferencia en materia de imagen $y$ normalmente de manera satisfactoria, ya que la etapa colonial se recuerda sin ningún tipo de recelo en este país.

El número de informaciones sobre temas económicos que relacionan a los dos países se mantiene estable en los dos períodos analizados, unas 60 noticias por semestre, cerca del 30\% del total de las informaciones de esta categoría. El contenido de las informaciones 
contabilizadas se centra exclusivamente en la actividad de empresas españolas en Costa Rica.

Asimismo, La República concentra el mayor número de notas por su enfoque económico y por el público al que va dirigido y por este mismo motivo, ofrece en términos generales una imagen positiva de la actividad de las empresas españolas. Pero incluso en este medio aparecen notas sobre los problemas medioambientales que acompañaron la construcción del Hotel Riu en la costa del Pacífico en 2009 o los fallos en la construcción de una de las vías fundamentales del país: la carretera que une la capital, San José, con el puerto de Caldera en el Pacífico por Autopistas del Sol, uno de los temas que más ha empañado la imagen de la inversión española en Costa Rica y al que se ha dedicado mayor espacio informativo. Esta cuestión propició las portadas más duras del Semanario Universidad, como la del 29 de julio de 2009, en el que a toda página se representa a la ministra de Obras Públicas montada en un coche con bandera española atropellando "los derechos costarricenses". El único tema al que La Nación dedica un amplio espacio en esta categoría es a la concesión del servicio técnico de inspección de vehículos de Costa Rica a la empresa española Riteve, la primera en entrar en el país y que sigue siendo objeto de polémicas por irregularidades en la concesión del servicio o abusos en el establecimiento de tarifas.

Para el lector costarricense, las inversiones de empresas españolas son el aspecto más polémico de las relaciones con España y por la forma en que está planteado, el tema que más influencia puede tener para elaborar una imagen de la relación bilateral. Las noticias publicadas en este apartado son mayoritariamente de elaboración propia por los diarios, eso implica que su enfoque está adaptado al público costarricense, informaciones puestas en contexto $y$ comprensibles para el lector, lo que aumenta su impacto, aunque el número siga siendo, como en todos los capítulos, reducido. A lo largo de 2012 , se redujo notablemente el número de informaciones relativas a Autopistas del Sol y se diversifican los temas con la entrada de nuevas empresas como Movistar, Mapfre o fcc que reflejan la cada vez mayor participación empresarial de España en todos los sectores.

INFORMACIONES SOBRE RELACIONES CULTURALES Y DEPORTIVAS ENTRE ESPAÑA Y COSTA RICA

Es el tema que informativamente revela mayores lazos entre los dos países y aunque el número de entradas desciende en casi seis puntos porcentuales en 2012 en relación con el segundo semestre de 2009, sigue representando casi la mitad de las noticias que en algún sentido relacionan a España con Costa Rica.

El motivo es que todo lo que un artista español haga en Costa Rica y todo lo que cualquier artista costarricense haga en España tiene una importante repercusión, incluso desproporcionada, en la prensa. De nuevo son nombres propios los que acaparan las relaciones o intercambios culturales entre los dos países, repitiéndose: Serrat y Sabina, José Luis Perales o Enrique Bumbury. Los conciertos - la música en general- domina el panorama en detrimento del cine o la literatura u otro tipo de expresiones artísticas, pero también tienen espacio en la prensa las actividades puntuales patrocinadas por la embajada de España o el Centro Cultural Español, lo que revierte en una buena imagen para el gobierno español, aunque con menos frecuencia de lo deseable.

En cuanto a las noticias que relacionan a ambos países en lo deportivo, el incremento en el número de noticias durante el segundo semestre de 2012 en relación a 2009, hasta el 19\% del apartado, tiene una razón muy concreta $y$ es el fichaje de dos futbolistas costarricenses por equipos de Primera División de España. Esta noticia se convierte en una fuente de información para el lector que supera con creces el ámbito deportivo al referirse de la historia de la ciudad que realiza el fichaje o incorporar semanalmente la crónica del partido en el que "los legionarios ticos" — como aquí se conoce a todos los jugadores que juegan en ligas europeas - han participado. Si no fuera por este hecho puntual, las noticias que relacionan en el terreno deportivo a España con Costa Rica serían muy reducidas. 
INFORMACIONES SOBRE LA RELACIÓN DE ESPAÑA CON AMÉRICA LATINA

Son proporcionalmente pocas las informaciones publicadas en la prensa de Costa Rica que relacionan en cualquier sentido a España con América Latina y además, hay que recalcar un muy significativo descenso en su número durante el segundo semestre de 2012 en relación con el mismo periodo de 2009: del $13 \%$ al $4 \%$ del total de informaciones publicadas relacionadas con España. Ello a pesar de la celebración en España de la Cumbre Iberoamericana y la conmemoración del segundo centenario de las Cortes de Cádiz que, realmente, tiene un seguimiento irregular y ninguna trascendencia informativa.

El lector de prensa costarricense sacará la conclusión de que España se relaciona con América Latina no en aspectos de política bilateral, proyectos comunes o cooperación, sino solo a través de grandes empresas inversoras que suelen tener problemas con determinados gobiernos del continente. Básicamente, se mencionan empresas como Repsol, Telefónica, los bancos Santander y ввvа. En 2012, se incluye Sacyr Vallehermoso por las obras de construcción del nuevo juego de esclusas del Canal de Panamá.

GRÁFICO 5

ENTRADAS ENTRE ESPAÑA-AMÉRICA LATINA

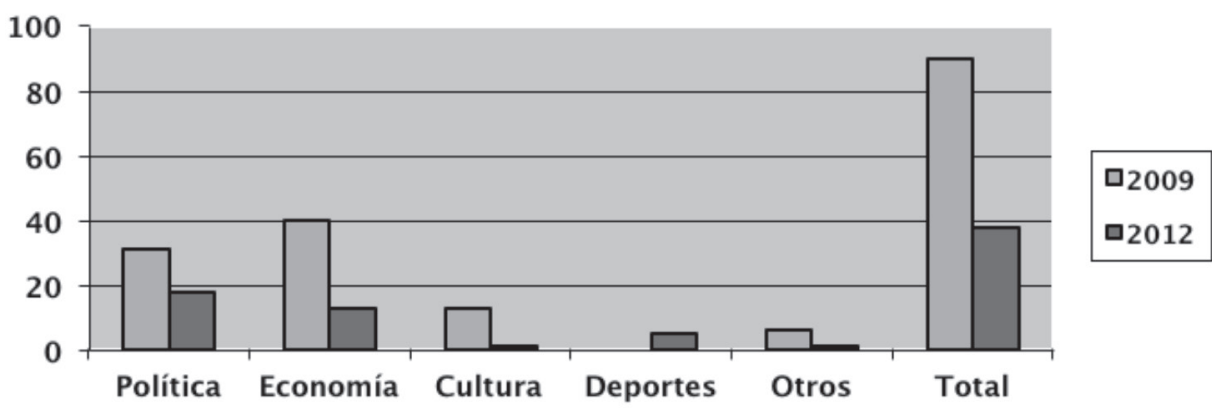

Fuente: Elaboración propia.

INFORMACIONES RELACIONADAS CON ESPAÑA QUE APARECEN EN PORTADA

Los temas que ocupan portadas no están determinados por su importancia informativa sino por criterios de diseño de los diferentes periódicos, que dedican espacios fijos en primera página para la información deportiva o las noticias de espectáculos.

La excepción a esta premisa la constituye la crisis, la cual ocupa dos portadas impactantes en el diario La Nación en el segundo semestre de 2012, al reflejar de forma expresiva el descontento social en España. El 12 de julio, la mayor parte de la primera página es ocupada por una foto de enfrentamientos entre policía y manifestantes con el pie de foto "Violencia en España". La segunda, el 17 de setiembre, bajo una gran foto de una manifestación en Madrid contra la política de austeridad: "Golpe de crisis: deuda saca de vivienda a millares de españoles: hay más de 46.000 procesos de desahucio en el primer trimestre del año". Las portadas de La República referidas a la crisis son más neutras: "Persisten riesgos para la banca española", "Se impone la deuda española", entre otros. 


\section{GRÁFICO 6 \\ NÚMERO DE PORTADAS RELACIONADAS CON ESPAÑA}

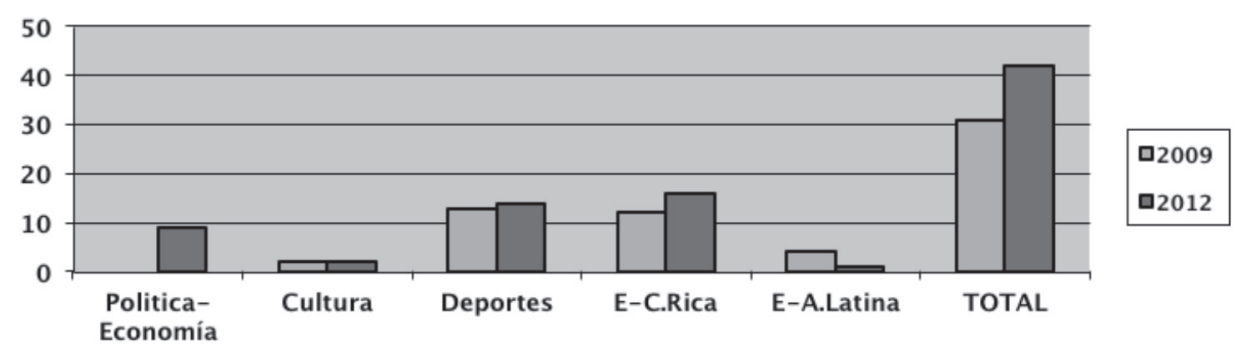

Fuente: Elaboración propia.

El número de portadas dedicadas a los problemas económicos en España es reducido y proporcionalmente mínimo en relación al número de espacios que en primera página ocupan las victorias de la selección española de fútbol o el tenista Rafael Nadal. Llama la atención que para el mes de julio, cuando en el interior de La Nación o La República se están abordando las más graves consecuencias de la crisis en España, los temas que tienen relevancia en primera página son el chupinazo de San Fermín, el triunfo de Fernando Alonso, el lanzamiento de una nueva fragancia de Loewe o las actuaciones de los artistas españoles.

\section{VALORACIÓN GENERAL DE LAS INFORMACIONES DE CARA A LA IMAGEN DE ESPAÑA}

Las informaciones favorables a la imagen de España superan con mucho en ambos periodos a aquellas que trasmiten una imagen negativa, aunque la diferencia se redujo notablemente en el segundo semestre de 2012 en relación a 2009. Si en esa fecha, la diferencia era de casi 50 puntos, tres años después es de solo 20 puntos porcentuales. La razón es el peso de las noticias relacionadas con la crisis que disparan el número de noticias negativas en la categoría de informaciones sobre la actualidad nacional española, la más numerosa.

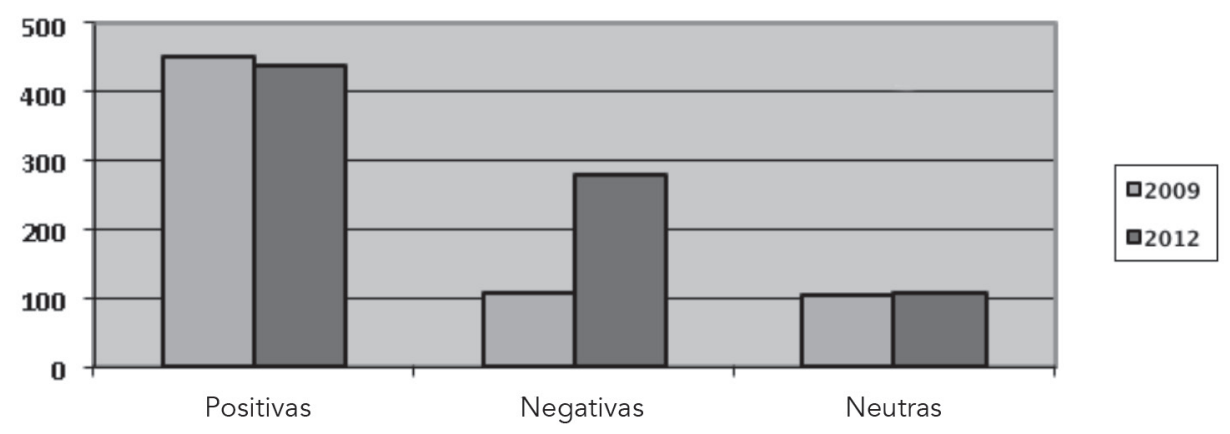

Fuente: Elaboración propia. 
En todos los periódicos analizados, el número de informaciones positivas sigue siendo mayor que el de noticias negativas. En $L a$ Nación y La República, la diferencia se redujo notablemente durante 2012 , dado que son estos dos diarios los que con más frecuencia reproducen noticias relativas a la crisis económica; no obstante, en La Nación, la diferencia se mantiene 20 puntos arriba para las noticias favorables a España.

Incluso, en el Diario Extra, durante 2012, las noticias presentan una mejor imagen de España, con un porcentaje mayor de noticias positivas (58\% frente al 46\% de 2009), debido en gran parte a los criterios, en la selección de sus noticias. Lo mismo ocurre en el caso del Semanario Universidad, aunque este periódico se centra de forma casi exclusiva en la información local, con lo que la cuestión de la crisis económica española no aparece reflejada en sus páginas.

\section{CONCLUSIONES}

España está muy presente en los medios escritos costarricenses y la imagen que se trasmite a través de la prensa costarricense es positiva.

El panorama positivo domina sobre lo negativo, incluso en los momentos más duros de la crisis. Es cierto que el fuerte aumento en el número de informaciones relativas a la crisis económica supone un fuerte varapalo para la imagen de España y eso es indudable. El que la mayoría de estas informaciones se publiquen en La Nación multiplica su efecto negativo ya que, por un lado, es el periódico más influyente $y$ por otro, es el que plantea las informaciones desde un punto de vista más coherente $y$ con mayor seguimiento, por lo que sus lectores podrán apreciar de forma más completa la gravedad de los efectos de la crisis. Pero no solamente en La Nación, sino en todos los medios, el número de noticias positivas relativas a la actualidad española o a España en relación con Costa Rica o con América Latina, es notablemente mayor al de noticias negativas.

Las informaciones sobre el deporte en España arrasan en los medios escritos costarricenses. Su frecuencia, su número y su tratamiento son mucho más amplios y mejores que los que pueda ofrecerse sobre cualquier otro tema y eso repercute positivamente en la imagen de España. Los titulares dedicados en algunos momentos a la selección española de fútbol podrían contrarrestar la carga negativa de diez noticias relacionadas con la economía.

Lo mismo, aunque no de forma tan exagerada, sucede con las noticias culturales o del mundo del espectáculo, aunque estas tienen contenidos más dispersos o están centradas en pocos nombres propios convertidos en embajadores de un mundo cultural español en el que no caben los libros, las artes plásticas o la producción cinematográfica.

Es la actividad de las empresas españolas la que adquiere cierta presencia en la prensa como canal de las relaciones entre Costa Rica y España, unas relaciones que no aparecen reflejadas en los medios en ningún otro sentido. $\mathrm{Su}$ actuación incorpora el factor más vulnerable para la imagen de España, ya que será analizado desde un punto de vista crítico $y$ elaborado por los medios. El comportamiento de sus directivos, la forma en que realizan sus inversiones, su respeto al medio ambiente o la legislación laboral, acaban valorándose como la forma de actuar de los propios ciudadanos de un país, las empresas se personalizan y se juzgan como sus representantes. La iniciativa y la inversión privada de estos grupos están sustituyendo a la acción de los gobiernos y de los propios ciudadanos como trasmisores de imagen en los medios. En todo caso, ese tipo de informaciones son relativamente escasas en comparación con las que protagonizan los artistas o representantes del mundo de la cultura o el espectáculo que llegan a Costa Rica y que tienen mucha repercusión en la prensa, aunque los que lleguen sean realmente pocos.

El lector de prensa de Costa Rica obtiene en líneas generales una imagen positiva de España basada en la fuerza de sus victorias deportivas y en la personalidad de algunas figuras destacadas entre sus artistas, principalmente del mundo de la música y el cine: Serrat, Sabina, Penélope Cruz o Pedro Almodóvar. Asimismo, se conoce que la familia real tiene algunos problemas pero, por la frivolidad con que se presentan, no parecen muy 
importantes y sobre todo, menos destacados que la influencia que pueda ejercer la ropa que vista doña Letizia. No se tendrá ni idea de los problemas de corrupción que afectan a los políticos españoles y tampoco se conocerá del esfuerzo de cooperación que España ha hecho en el país. Probablemente, el lector de prensa costarricense tendrá dificultades para recordar el nombre del presidente de gobierno; sabrá que una parte de España quiere independizarse pero sin entender muy bien el porqué; le quedará claro que algo anda mal con la economía aunque sean las empresas españolas las que parezca que quieran hacerse con la mayoría de las obras que ofrezca en concesión el gobierno de Costa Rica; sabrá que esas empresas plantean en muchos casos problemas de medio ambiente en el país y que pueden aprovecharse de determinadas condiciones económicas de Costa Rica; sabrá que España es un país permisivo con el aborto $y$ los homosexuales, pero que tiene problemas con los inmigrantes.

Por supuesto que es una imagen incompleta y superficial, por lo cual, el lector de los medios de prensa, no recibirá demasiados elementos de juicio para entender, a través de las informaciones publicadas, la cuestión de las autonomías o las razones de la crisis económica. Pero lo cierto es que, a efectos de imagen, tiene más posibilidades de obtener una percepción positiva de España que de conocer el lado negativo.

No hay nada que diferencie a España del tratamiento informativo que se le da a otros países. Las noticias que tienen a España como protagonista en cualquier ámbito están bien o mal planteadas como las referidas al resto. Las noticias sobre la actualidad internacional no son una prioridad en ningún periódico estudiado, se limitan a reproducir de forma poco coherente y poco elaborada los cables de las agencias internacionales.

\section{BIBLIOGRAFÍA}

LIBROS

Anholt, Simon. Places, identity, images and Reputation. New York: Palgrave Macmillan, 2010.
Fombrum, Charles. Reputation: realizing Value from the corporate image. Harvard Bussines School, 1996

Ordoñez Chacón, Jaime (director de proyecto). ¿Hacia dónde va Costa Rica? Sistema político y escenarios de gobernabilidad democrática para la próxima década 2010-2020: 5 debates sobre el futuro de Costa Rica. San José, Costa Rica: Asociación Estudios para el Futuro, 2009

Díaz Nosty, Bernardo (Director). Medios de comunicación, el escenario iberoamericano. Editorial ArielFundación Telefónica-Editorial Planeta, 2007.

Noya Miranda, J. Diplomacia pública para el siglo xxı. Editorial Ariel. Real Instituto Elcano. Madrid, 2007.

Noya Miranda, J. La nueva imagen de España en América Latina. Madrid, España: Editorial Tecnos y Real Instituto Elcano, 2009.

\section{PUBLICACIONES PERIÓDICAS}

Diario Extra. Todos los ejemplares de 01/08/ 2009 al 31/09/2009. San José, Costa Rica. Hemeroteca de la Biblioteca Nacional de San José, Costa Rica.

Diario Extra. Todos los ejemplares de 01/08/ 2012 al 31/09/2010. San José, Costa Rica. Hemeroteca de la Biblioteca Nacional de San José, Costa Rica.

Periódico La Nación. Todos los ejemplares de 01/08/ 2009 al 31/09/2009. San José, Costa Rica. Hemeroteca de la Biblioteca Nacional de San José, Costa Rica.

Periódico La Nación. Todos los ejemplares de 01/08/ 2012 al 31/09/2010. San José, Costa Rica. Hemeroteca de la Biblioteca Nacional de San José, Costa Rica.

Periódico La República. Todos los ejemplares de 01/08/ 2009 al 31/09/2009. San José, Costa Rica. Hemeroteca de la Biblioteca Nacional de San José, Costa Rica.

Periódico La República. Todos los ejemplares de 01/08/ 2012 al 31/09/2010. San José, Costa Rica. Hemeroteca de la Biblioteca Nacional de San José, Costa Rica. 
Semanario Universidad. Todos los ejemplares de 01/08/ 2009 al 31/09/2009. San José, Costa Rica. Hemeroteca de la Biblioteca Nacional de San José, Costa Rica.

Semanario Universidad. Todos los ejemplares de 01/08/ 2012 al 31/09/2010. San José, Costa Rica. Hemeroteca de la Biblioteca Nacional de San José, Costa Rica.

TESIS

Núñez Aberturas, María de los Ángeles. "La imagen de España en Centroamérica, El caso de Costa Rica”. [Tesis Doctoral]. España, Universidad Nacional de Educación a Distancia (UNED), 2015.

OTROS

Informe Corporación Latinobarómetro. América Latina mira al mundo. La globalización y las relaciones con otros países del mundo. Santiago de Chile, 2010. En <https://www.oas.org/en/ ser/dia/outreach/docs/Informe $\% 20$ Latinobarometro\%20Cooperacion_en_ America_Latina\%5B1\%5D\%202010.pdf>

Ordoñez Chacón, Jaime. ¿Hacia dónde va Costa Rica? Sistema político y escenarios de gobernabilidad democrática para la próxima década 2010-2020: 5 debates sobre el futuro de Costa Rica. San José, Costa Rica: Asociación Estudios para el Futuro, 2009.

Real Instituto Elcano de Informes Estratégicos. En $<w w w . r e a l i n s t i t u t o e l c a n o . o r g>$

Reputation Institute. En $<w w w$. reputationinstitute.com>

\section{ENTREVISTAS}

Alejandro Urbina. Director periódico La Nación (entre abril de 2003 y marzo de 2010). Realizada en abril de 2010.

Laura Martínez Quesada. Directora periódico Semanario Universidad (entre julio de 2003 y septiembre de 2012). Realizada en marzo de 2010.

Luis Alberto Muñoz. Director periódico La República (entre 2003 y 2012). Realizada en abril de 2010.

Fecha de ingreso: 07/05/2014 Fecha de aprobación: 19/11/2014 